\title{
Antarctic surface melting dynamics: Enhanced perspectives from radar scatterometer data
}

\author{
L. D. Trusel, ${ }^{1}$ K. E. Frey, ${ }^{1}$ and S. B. Das ${ }^{2}$ \\ Received 22 June 2011; revised 1 March 2012; accepted 2 April 2012; published 17 May 2012.
}

[1] Antarctic ice sheet surface melting can regionally influence ice shelf stability, mass balance, and glacier dynamics, in addition to modulating near-surface physical and chemical properties over wide areas. Here, we investigate variability in surface melting from 1999 to 2009 using radar backscatter time series from the SeaWinds scatterometer aboard the QuikSCAT satellite. These daily, continent-wide observations are explored in concert with in situ meteorological records to validate a threshold-based melt detection method. Radar backscatter decreases during melting are significantly correlated with in situ positive degree-days as well as meltwater production determined from energy balance modeling at Neumayer Station, East Antarctica. These results support the use of scatterometer data as a diagnostic indicator of melt intensity (i.e., the relative liquid water production during melting). Greater spatial and temporal melting detected relative to previous passive microwave-based studies is attributed to a higher sensitivity of the scatterometer instrument. Continental melt intensity variability can be explained in part by the dynamics of the Southern Annular Mode and the Southern Oscillation Index, and extreme melting events across the Ross Ice Shelf region may be associated with El Niño conditions. Furthermore, we find that the Antarctic Peninsula accounts for only $20 \%$ of Antarctic melt extent but greater than $50 \%$ of the total Antarctic melt intensity. Over most areas, annual melt duration and intensity are proportional. However, regional and localized distinctions exist where the melt intensity metric provides greater insight into melting dynamics than previously obtainable with other remote sensing techniques.

Citation: Trusel, L. D., K. E. Frey, and S. B. Das (2012), Antarctic surface melting dynamics: Enhanced perspectives from radar scatterometer data, J. Geophys. Res., 117, F02023, doi:10.1029/2011JF002126.

\section{Introduction}

[2] Although most Antarctic ice sheet surface melt refreezes within the near-surface snow and firn, a comprehensive understanding of this process remains important in numerous physical, climatological, and glaciological contexts. Melt detection provides insight into near-surface air temperatures and energy budgets. Such observations are scarce across the expansive Antarctic continent and are particularly valuable because of the numerous couplings between Antarctica and the global climate system [e.g., King and Turner, 1997]. Melting plays a critical role in the surface energy balance by reducing albedo [e.g., Kuipers

\footnotetext{
${ }^{1}$ Graduate School of Geography, Clark University, Worcester, Massachusetts, USA.

${ }^{2}$ Department of Geology and Geophysics, Woods Hole Oceanographic Institution, Woods Hole, Massachusetts, USA.

Corresponding author: L. D. Trusel, Graduate School of Geography, Clark University, 950 Main St., Worcester, MA 01610, USA. (ltrusel@clarku.edu)

Copyright 2012 by the American Geophysical Union. 0148-0227/12/2011JF002126
}

Munneke et al., 2011], causing increased solar radiation absorption leading to a positive feedback with the potential to produce additional melting [Picard et al., 2007]. Furthermore, liquid water percolation and refreezing modifies the snowpack energy budget, density, morphology, and isotopic signature [Cuffey and Paterson, 2010].

[3] While these broad and important implications exist across the Antarctic continent, nowhere is surface melting more impactful than on the Antarctic Peninsula. Here, surface ablation contributes to mass losses through runoff [Vaughan, 2006; Hock et al., 2009] and studies implicate its role in the breakup of several ice shelves, including the catastrophic collapse of Larsen B in 2002 [Scambos et al., 2000; van den Broeke, 2005]. Whereas ice shelf breakup has little direct influence on sea level [Shepherd et al., 2010], the likely repercussions certainly may: Pronounced flow accelerations of land-based tributary glaciers were observed following the Larsen B collapse [Rignot et al., 2004; Scambos et al., 2004]. Furthermore, glaciers of the western Antarctic Peninsula may be dynamically responding to surface melt-induced thinning, contributing to sea level at a magnitude similar to that of Alaskan glaciers [Pritchard and Vaughan, 2007]. Although research demonstrates that 
Antarctic Peninsula ice shelves follow a thermal limit of viability [Morris and Vaughan, 2003], surface melting plays a complex and coupled role with other processes such as oceanic warming in governing ice dynamics [Cook and Vaughan, 2010]. Elucidation of the complex drivers of ice shelf and glacier behavior requires understanding not only the variability of surface melting, but critically also its magnitude.

[4] Antarctic surface melting has been studied extensively utilizing satellite passive microwave (PMW) radiometers such as the Scanning Multichannel Microwave Radiometer (SMMR) and the Special Sensor Microwave Imager (SSM/I) [e.g., Torinesi et al., 2003; Liu et al., 2006; Picard and Fily, 2006; Tedesco, 2009]. This work extends back to 1978 and forms the foundation of our knowledge on Antarctic surface melting dynamics by documenting its spatiotemporal variability as well as important linkages to global climatic phenomena [Tedesco and Monaghan, 2009]. However, because microwave brightness temperature (the basis for radiometer melt detection) saturates at small fractions of liquid water content (LWC), these instruments generally provide only binary information indicating the presence or absence of melt. This is a critical limitation, particularly in the context of understanding many of the glaciological consequences of melting since it largely ignores the melt intensity (i.e., liquid water production during melting).

[5] Active microwave (radar) scatterometers have likewise proven to be a valuable source of information for monitoring melting processes over Greenland [e.g., Nghiem et al., 2005; Wang et al., 2007], glaciers and ice caps in the Arctic [e.g., Wang et al., 2005; Wolken et al., 2009], Arctic sea ice [e.g., Frey et al., 2003], and low-latitude alpine regions [e.g., Panday et al., 2011]. In comparison, relatively few studies [Kunz and Long, 2006; Nghiem et al., 2007] have employed scatterometers to detect and study Antarctic surface melting. Although providing a more limited observational time series length relative to PMW radiometers, scatterometers afford a greater sensitivity to melt [Steffen et al., 2004; Ashcraft and Long, 2006; Tedesco, 2007] and higher spatial resolutions [Long, 2010]. Most importantly, previous research has demonstrated significant correlations between seasonally summed radar backscatter reductions during melting and positive degree-days (PDD) (i.e., temporally integrated positive air temperatures) [Wismann, 2000], suggesting the potential for these backscatter reductions to therefore serve as a proxy for melt intensity [Smith et al., 2003]. Unlike other remote sensing instruments, scatterometers offer the potential for melt intensity retrieval, although this potential is so far severely understudied.

[6] In this study, we exploit the aforementioned benefits of scatterometers for melt detection across the continent of Antarctica using enhanced resolution data from the SeaWinds radar scatterometer aboard the QuikSCAT satellite (hereafter simply QuikSCAT). We construct a melt time series using a threshold-based detection algorithm that spans 10 melt seasons from 1999 to 2009 . We explore these data in concert with in situ meteorological records from a number of weather stations across Antarctica to calibrate and validate melt presence and relative melt intensity. Previously unobtainable insight provided by the melt intensity metric, potentially applicable for quantitative derivation of $\mathrm{LWC}$, enables a more encompassing view of Antarctic melting dynamics and improves upon limitations of past studies.

\section{Data and Methods}

\subsection{Data}

\subsubsection{Satellite Data}

[7] Spaceborne data used in this study are derived from the Ku-band (13.4 GHz) QuikSCAT. The instrument allows for normalized radar cross-section backscatter $\left(\sigma^{0}\right)$ measurements at two constant incident angles of $46^{\circ}(1400 \mathrm{~km}$ swath) and $54^{\circ}$ (1800 km swath) for the horizontally polarized inner beam and vertically polarized outer beam, respectively. Utilizing the multiple daily polar overpasses, multidaily data with enhanced spatial resolutions are produced using the Scatterometer Image Reconstruction (SIR) algorithm [Long, 2010]. These data are therefore enhanced from their native $\sim 25 \mathrm{~km}$ spatial resolution to $4.45 \mathrm{~km}(\sim 8$ $10 \mathrm{~km}$ effective) for the "egg" data used here [Long, 2010]. We use vertically polarized QuikSCAT data following recent studies [Ashcraft and Long, 2006; Rotschky et al., 2011] and limit observations to afternoon local time-of-day (1200-2000 h) [Hicks and Long, 2005] for temporal correspondence with peak insolation and assumed melting. The $\sigma^{0}$ time series covers 10 austral summer melt seasons from July 1999 to November 2009, when the satellite antenna failed. To avoid splitting the summer, melt years are defined as day 201 of the first year to day 200 of the second year, and are simply referred to by the second year (i.e., summer $1999-2000$ is 2000).

\subsubsection{In Situ and Ancillary Data}

[8] Calibration and validation of remotely sensed melt detection is best achieved using ground data that directly document melting. Determination of actual meltwater production requires energy balance observations that are lacking over most of Antarctica. In their absence, however, nearsurface air temperature is a reliable proxy for melt presence because of its strong correlations with the primary variables governing melting: incoming shortwave and longwave radiation, and the sensible heat flux [Ohmura, 2001]. Further justifying the use of air temperature data, the magnitude of temperatures above $0^{\circ} \mathrm{C}$ (i.e., PDD) are strongly correlated with liquid water production during snow and ice melting [Hock, 2005] as well as the formation of near-surface meltrelated features in polar firn [Das and Alley, 2005]. Thus, air temperature data enable both validations of melt presence/ absence and estimation of melt intensity (liquid water production).

[9] Harnessing these relationships, we examine correlations between melting signatures from QuikSCAT and air temperature data from the National Climatic Data Center (NCDC) Global Surface Summary of the Day (GSOD) database comprised of meteorological data from World Meteorological Organization stations. For Antarctica, these include an international array of automated weather stations (AWS) and staffed weather stations at permanent research bases, all herein referred to as AWS (Figure 1). The NCDC GSOD database provides single daily measurements derived from raw data collected at varying temporal resolutions ranging from 10-min to 3-hourly intervals. Eleven AWS were selected to span a wide range of melting regimes, with emphasis placed on temporal data continuity during austral 


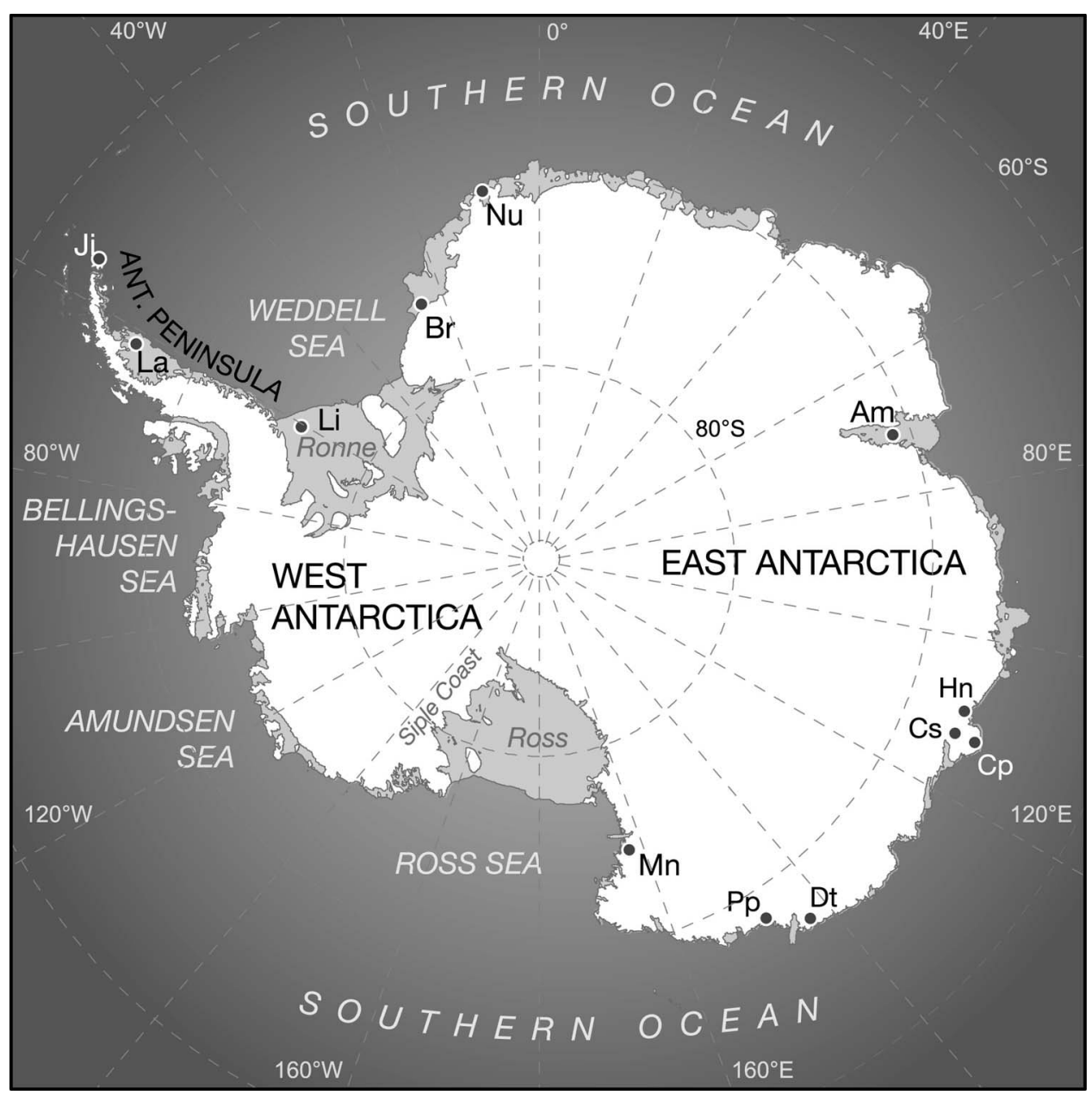

Figure 1. Location map showing major geographic provinces. Land/ice is shown in white and ice shelves in gray. Locations of NCDC AWS sites used in this study are shown as black dots (Ji: Joinville Island; La: Larsen C; Li: Limbert; Br: Brunt; Nu: Neumayer; Am: Amery; Hn: Haupt Nunatak; Cs: Casey Skiway; Cp: Cape Poinsett; Pp: Penguin Point; Mn: Manuela). The D-10 AWS (Dt) is only available via the AMRC.

summer, data quality, and reduction of mixed pixel effects (e.g., ocean/ice, bare ground/ice, high relief areas). To provide further validation of melt intensity using higher temporal resolution data (3-hourly observations), we examine an additional temperature data set available from the University of Wisconsin Antarctic Meteorological Research Center (AMRC). These AMRC stations include Larsen C, Limbert, Manuela, and D-10 (Figure 1). Meltwater production data modeled by van den Broeke et al. [2010] at Neumayer Station on the Ekström Ice Shelf provide an additional source for ground truthing.

[10] Geospatial data from the MODIS Mosaic of Antarctica [Haran et al., 2005] are used as an ice mask and to delineate continental and ice shelf margins. Boundaries of the Larsen B ice shelf were manually added to this data set using mapped terminus positions [Cook and Vaughan, 2010] for the period 1999-2002, before its ultimate collapse.

\subsection{Methods}

\subsubsection{Melt Detection}

[11] We employ a dynamic, threshold-based melt detection approach in each QuikSCAT pixel for the entire 1999-
2009 time series. This approach relies on the highly contrasting dielectric properties of liquid and frozen water [e.g., Stiles and Ulaby, 1980]. The high dielectric constant of liquid water greatly reduces volume scattering while increasing microwave absorption, resulting in dramatically reduced $\sigma^{0}$ with the presence of even small fractions of snowpack LWC [Stiles and Ulaby, 1980]. Progressive exposure of bare ice [Wang et al., 2005] and near-surface ice lenses [Kendra et al., 1998] may result in pronounced surface scattering during melting; however, such cases are exceptional [Kendra et al., 1998] and generally masked by the dominant effect of decreased volume scattering with the presence of snowpack LWC [Wang et al., 2005]. The logic behind our melt detection method follows Wang et al. [2005, 2007], but is necessarily modified to account for the influence of snow accumulation in some areas.

[12] Melting days are determined following a decision tree that compares the output of four detection algorithms with varying thresholds in addition to the temporal backscatter characteristics in each pixel. See the online auxiliary material (OAM) for a detailed description of alternative detection algorithms designed to prevent false detection 


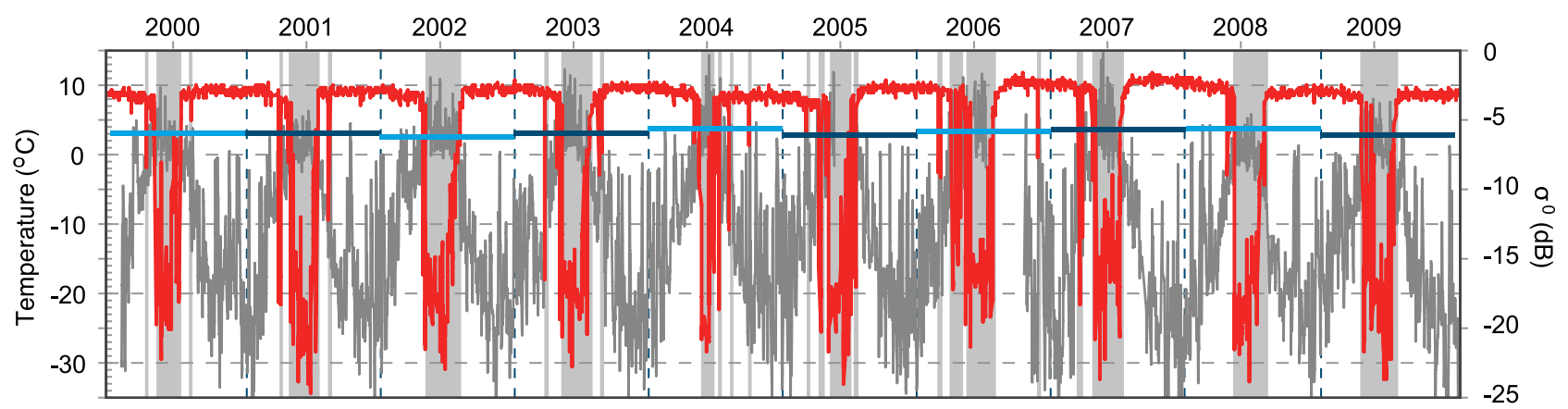

Figure 2. An example time series of QuikSCAT $\sigma^{0}$ (red line) and maximum daily temperature (gray line) at the Larsen $\mathrm{C}$ ice shelf AWS (see Figure 1 for location). Variable yearly melt thresholds for this site are shown (horizontal blue bars). When $\sigma^{0}$ drops below this value, the day is characterized as melting according to equation (1), shown here as vertical gray boxes.

owing to gradual snowfall-induced $\sigma^{0}$ reductions. ${ }^{1}$ Although we find this multithreshold approach necessary, $94 \%$ of all melting was determined using a single, constant threshold below a dynamic winter mean $\sigma^{0}$. Thus, the primary algorithm specifies for every day $(i)$ in each pixel, a melting day $(M D)$ is defined as:

$$
\begin{array}{lll}
M D=1, & \text { if } & \sigma_{i}^{0}<\left(\overline{\sigma_{w}^{0}}-b\right) \\
M D=0, & \text { if } & \sigma_{i}^{0} \geq\left(\overline{\sigma_{w}^{0}}-b\right)
\end{array}
$$

where $\sigma_{i}^{0}$ is the daily backscatter value for a pixel in $\mathrm{dB}, \overline{\sigma_{w}^{0}}$ is the mean austral winter backscatter (July-September) preceding the melt season determined for each pixel, and $b$ is a constant threshold describing the required backscatter reduction in $\mathrm{dB}$ for a day to be characterized as melting. Thus, if $\sigma_{i}^{0}$ drops below the threshold $(b)$ from $\overline{\sigma_{w}^{0}}$, it is characterized as a melting day $(M D=1)$ (Figure 2). The value of $b=2 \mathrm{~dB}$ was empirically determined through careful examination of backscatter variability in direct consultation with AWS data (see OAM for a detailed sensitivity analysis). This value is consistent with empirically derived constants used by other recent QuikSCAT studies: 2 and $3 \mathrm{~dB}$ by Wang et al. [2007] for Greenland, $1.7 \mathrm{~dB}$ for pan-Arctic snowmelt [Wang et al., 2008], and $1.65 \mathrm{~dB}$ used by Rotschky et al. [2011] over Svalbard. As our methodology considers any day below the threshold as melting, it is more sensitive to brief melting events (particularly at the margins of the melt season) relative to studies intended to detect only "persistent" (i.e., multiday) melting [e.g., Wang et al., 2007; Tedesco et al., 2007].

[13] It is important to consider the implications of using a $2 \mathrm{~dB}$ threshold for most of the study region. Equating a single threshold to a specific snowpack LWC is infeasible owing to the dependence of $\sigma^{0}$ on additional factors including wet snow layer thickness and other inherent snowpack properties [Winebrenner et al., 1994; Nghiem et al., 1995; Ulaby et al., 1996]. Thus, to understand the potential range of LWC implications of a $2 \mathrm{~dB}$ threshold, we review the literature. Utilizing C-band $(5.3 \mathrm{GHz})$ measurements, Nagler and Rott [2000] found an upper snowpack layer with $1 \%$ wetness

\footnotetext{
${ }^{1}$ Auxiliary materials are available in the HTML. doi:10.1029/ 2011JF002126.
}

resulted in a $2 \mathrm{~dB} \sigma^{0}$ reduction. Ashcraft and Long [2006] modeled the $\mathrm{Ku}$-band $(13.4 \mathrm{GHz})$ response to wetness, finding that a $3.8 \mathrm{~cm}$ snow layer with $1 \% \mathrm{LWC}$ results in a $\sigma^{0}$ reduction of $3 \mathrm{~dB}$. This value is comparable with experimentally determined dynamic responses to $1.3 \%$ LWC, ranging from $\sim 3.5 \mathrm{~dB}$ (at $8.6 \mathrm{GHz}$ ) to $\sim 8 \mathrm{~dB}$ (at $17 \mathrm{GHz}$ ) [Stiles and Ulaby, 1980]. We can therefore confidently assume that a $2 \mathrm{~dB}$ threshold using $13.4 \mathrm{GHz}$ QuikSCAT data should represent an upper snowpack of less than $\sim 1 \%$ LWC by volume, making our detection scheme highly sensitive. This LWC value compares favorably with PMW melt detection algorithms based on modeled wetness values of $0.2-0.5 \%$ in Tedesco et al. [2007], and $0.1 \%$ and $0.2 \%$ in Tedesco [2009].

\subsubsection{Melt Intensity}

[14] Theoretical and experimental research documents an overall inverse relationship between snowpack wetness and radar backscatter [Stiles and Ulaby, 1980; Nghiem and Tsai, 2001; Nghiem et al., 2001]. Although snowpack properties can confound direct quantification of LWC from $\sigma^{0}[$ Nghiem et al., 2001], empirical research demonstrates a near-linear $\sigma^{0}$ response to LWC up to a certain threshold ( $\sim 5 \%$ or greater) across a variety of radar frequencies [Stiles and Ulaby, 1980; Ulaby and Stiles, 1981]. Thus, as Wismann [2000] noted, the total decrease in $\sigma^{0}$ remains a function of total snowpack LWC, enabling estimation of at least relative LWC changes from $\sigma^{0}$. Employing this backscatter-wetness relationship, researchers empirically demonstrated that the magnitude and duration of C-Band $\sigma^{0}$ reductions during melting are proportional to PDD during a melt season [Wismann, 2000; Smith et al., 2003]. Because both PDD and $\sigma^{0}$ reductions are related to the total LWC produced during melting, this work established C-band scatterometer $\sigma^{0}$ reductions as a proxy for annual relative melt intensity. Following this logic, we examine the applicability of $\mathrm{Ku}$-band approximations of Antarctic melt intensity. For every day in the QuikSCAT time series $(i)$ in all pixels, the seasonally summed melting decibel-days (MDD in dB days), for each austral summer melt season are computed according to:

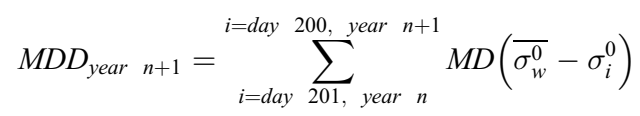



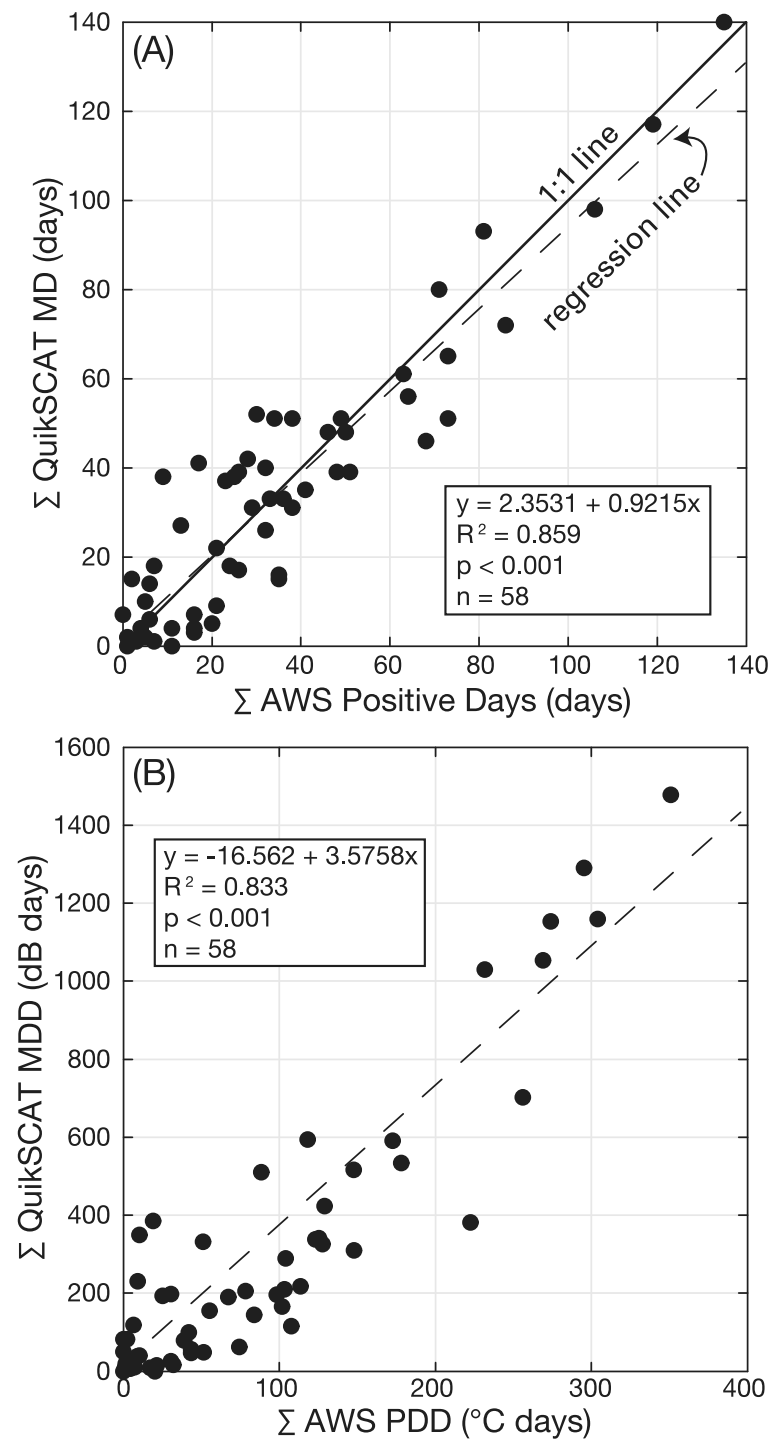

Figure 3. Plot of the dependence of (a) annual QuikSCAT melting days (MD) on annual positive days (PD) and (b) annual QuikSCAT melting decibel days (MDD) and annual positive degree-days (PDD) at the NCDC AWS shown in Figure 1. Regression lines are dashed.

where $\sigma_{i}^{0}$ is the daily backscatter value for a pixel in $\mathrm{dB}, \overline{\sigma_{w}^{0}}$ is the mean austral winter backscatter from year $n$ in $\mathrm{dB}$ as described in equation (1), and $M D$ is a binary function expressing the presence or absence of melting as determined in equation (1). Thus, if melt is detected on any given day $(M D=1)$, the daily reduction in $\sigma^{0}$ from the pixel's baseline $\overline{\sigma_{w}^{0}}$ is measured. When summed over the melt season, a total annual MDD term is produced to describe the annual relative melt intensity for each pixel.

\section{Results}

\subsection{Melt Detection Validation}

[15] We evaluate our melt detection algorithm (equation (1)) using the compiled NCDC AWS temperature observations. For each year, we sum the total annual days with maximum daily temperatures $>0{ }^{\circ} \mathrm{C}$ (Positive Days, PD) and likewise sum the total annual MD at these sites. We find a statistically significant, positive linear relationship between these two variables (Figure 3a), validating successful melt detection and the efficacy of our algorithm. Point scatter around the 1 to 1 line (Figure 3a) may be predominantly associated with maximum daily air temperature being an imperfect proxy for melt presence. For example, surface inversion can cause positive air temperatures at 2-3 m (typical AWS screen height), but freezing temperatures at the surface [e.g., Torinesi et al., 2003]. Likewise, temperature may only briefly exceed $0^{\circ} \mathrm{C}$ (and be reflected in our maximum temperature data), but the surface energy balance may remain negative. Conversely, positive energy balances can lead to melt during negative air temperatures [e.g., Liston and Winther, 2005] and snowpack liquid water can exist even after air temperatures drop below freezing. QuikSCAT is known to detect liquid water in the subsurface after surface refreeze [Ashcraft and Long, 2006; Hall et al., 2009], and the slightly positive intercept in Figure 3a (although not statistically different than 0 ) suggests we detect some melt during freezing air temperatures (potentially in the subsurface). Regardless of the varied contributors to the minor point scatter observed, the MD-PD relationship is robust and validates our detection approach.

\subsection{Melt Intensity Validation}

[16] To examine the applicability of MDD as a metric for melt intensity, we linearly regressed MDD values obtained using equation (2) with total PDD derived from maximum daily temperature data at the 11 NCDC AWS sites (Figure 1). We find a statistically significant, positive linear relationship between total MDD and total PDD across a geographically and climatologically diverse array of AWS sites (Figure $3 b$ ). This MDD-PDD relationship indicates that MDD can indeed be used as a proxy for melt intensity since PDD directly relate to liquid water production [e.g., Hock, 2005]. Some point scatter (Figure 3 b) is likely due to spatially variable meltwater production under consistent PDD owing to factors including background snow temperature, albedo, and specifics of the energy balance [Hock, 2005]. Whereas Smith et al. [2003] discuss a potential $\sigma^{0}$ saturation point at which melting fails to produce further $\sigma^{0}$ reductions, the linear relationship in Figure $3 \mathrm{~b}$ does not indicate saturation. Even if saturation points exist beyond the AWS sites, MDD should at minimum represent the relative melt intensity owing to its dual incorporation of melt season duration and $\sigma^{0}$ reductions.

[17] NCDC GSOD data allow for continental-scale in situ validation but are limited to single, daily temperature values. Thus, to further examine the efficacy our maximum daily temperature-based PDD melt intensity validation (Figure 3b), we perform a second linear regression between MDD (from equation (2)) and PDD calculated from 3-hourly measurements at AMRC AWS sites. This PDD term is calculated similarly to Das and Alley [2005] as the daily sum of $>0^{\circ} \mathrm{C}$ temperatures multiplied by their fractional daily representation (1/8 of a day). Higher temporal resolution AMRC data incorporate more detailed information on daily temperature variability and should therefore better reflect potential melt intensity (compared to the NCDC GSOD data), although their limited availability 

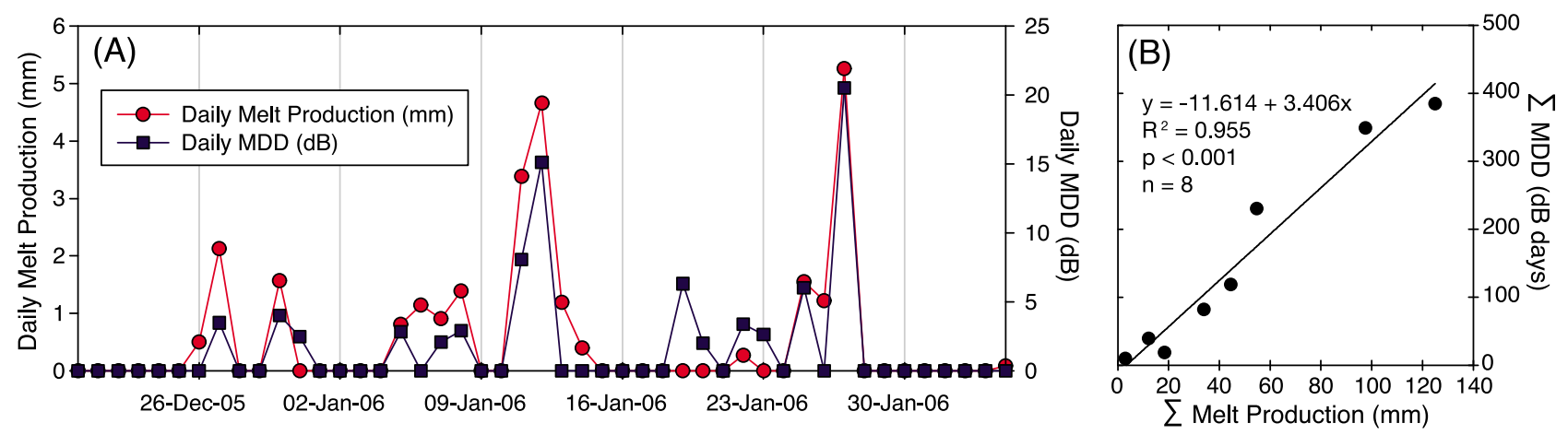

Figure 4. Comparison of QuikSCAT melt intensity to in situ melt determined by van den Broeke et al. [2010] using a surface energy balance model at Neumayer Station for (a) days in the 2006 melt season and (b) annual totals for 2000-2008.

and geographic distribution preclude widespread use in this study. Nevertheless, the AMRC regression reveals a similarly strong relationship $\left(\mathrm{r}^{2}=0.939, \mathrm{MDD}=-86.425+\right.$ $21.777 *$ PDD, $\mathrm{p}<0.001, \mathrm{n}=24)$ to that of the NCDC-based validation (Figure $3 \mathrm{~b}$ ) and therefore confirms our use of maximum temperature PDD (and thus MDD) as a proxy for melt intensity.

[18] As an independent test of QuikSCAT melt detection and MDD-based melt intensity, we examine correlations between MDD and liquid water production determined by van den Broeke et al. [2010] using surface energy balance (SEB) modeling at Neumayer Station (Figure 4). Over the Dec. 2005-Jan. 2006 melt season, variations in modeled melt rates predict $80 \%$ of the variance in daily QuikSCAT $\sigma^{0}$ reductions below the winter mean (i.e., "daily MDD"). The total number of melting days determined by each method over this summer is in close agreement: SEB modeling predicts 19 melting days (>0 mm melt) compared to 14 days of QuikSCAT. During this summer, there are 6 melting days found by the SEB model not detected by QuikSCAT, compared to 4 melting days observed by QuikSCAT not detected by SEB modeling (Figure 4a). Notably, two peaks in meltwater production (Jan. 12 and 27) mirror peaks in daily MDD and three less intense melt events correspond to proportionally smaller reductions in backscatter (Figure 4a). During the eight years of overlap (2000-2008), a very strong and significant correlation exists between annual in situ melt production ( $\mathrm{mm}$ of liquid water) and MDD at Neumayer Station (Figure 4b). Thus, although some discrepancies exist on a daily basis (potentially related spatial or temporal disagreement between observation methods, SEB model uncertainty, and/or snowpack variability), annual sums of SEB meltwater production explain $95 \%$ of the variance in annual QuikSCAT MDD and add further confidence in MDD as a direct metric of melt intensity.

\subsection{Continental Scale Melt Metrics}

\subsubsection{Temporal Melting Dynamics}

[19] Three primary metrics are used to analyze the overall spatial and temporal melting characteristics. The most basic parameter is total areal melt extent $\left(\right.$ in $\left.\mathrm{km}^{2}\right)$, calculated by multiplying each pixel where melting occurred on at least 1 day by its QuikSCAT pixel area $\left(19.8025 \mathrm{~km}^{2}\right)$. Following Zwally and Fiegles [1994], the second metric is known as the melt index $\left(\mathrm{km}^{2}\right.$ days), calculated as the product of pixel area and total annual melt duration in that pixel, summed for all pixels experiencing melt within an area of interest. The melt index, also known as the cumulative melting surface (CMS), is a commonly used metric because it incorporates both spatial and temporal dimensions of melting. Finally, total annual melt intensity (quantified here as MDD according to equation (2)) is summed for all pixels experiencing melt within a given area of interest.

[20] Investigation of all three metrics across the whole Antarctic continent reveals no clear trend over the 10-year study period (Figure 5). Overall the signs and relative magnitudes of interannual variability are similar among the metrics. In general, all three melt metrics trend upwards to mid-decade maxima in 2005. Following this peak, there is an overall decreasing trend toward the end of the decade. The minimum melting across the continent occurs in 2000 .

[21] Although there are clear, strong correlations among melt extent, index, and intensity, subtle but important disparities between them also exist. While all metrics peak in 2005, melt extent sharply decreases in 2006 even though the melt index and intensity remain high (Figure 5). These results indicate a less extensive melt in 2006 , but one that likely melted for both a longer duration and at greater intensity (i.e., with melt index and MDD values near their 2005 levels, respectively, but over a much reduced spatial extent). Although of smaller magnitude, similar dynamics are observed in the last two years of the record. Melt extent decreases while both the melt index and intensity increase from 2008 to 2009 (i.e., while a smaller area melted in 2009, the duration and strength of that melt exceeded that of 2008). Even if showing similar sign, the relative magnitude of interannual variability in melt metrics yields additional insight. For example, melt extent and index increase similarly (4\% and 5\%, respectively) from 2002 to 2003, yet melt intensity increases at a rate nearly double that $(9 \%)$ for the same time period. This greater increase in melt intensity implies more liquid water production (e.g., Figure $4 b$ ) over the continent in 2003 compared to 2002, potentially corresponding to warmer air temperatures (e.g., Figure $3 b$ ).

\subsubsection{Spatial Melting Dynamics}

[22] Figure 6 shows annual maps of melt duration anomalies calculated by subtracting yearly melt durations from the mean over 2000-2009. In agreement with previous findings [e.g., Liu et al., 2006; Tedesco et al., 2007], we find that melting is generally confined to lower elevation areas 


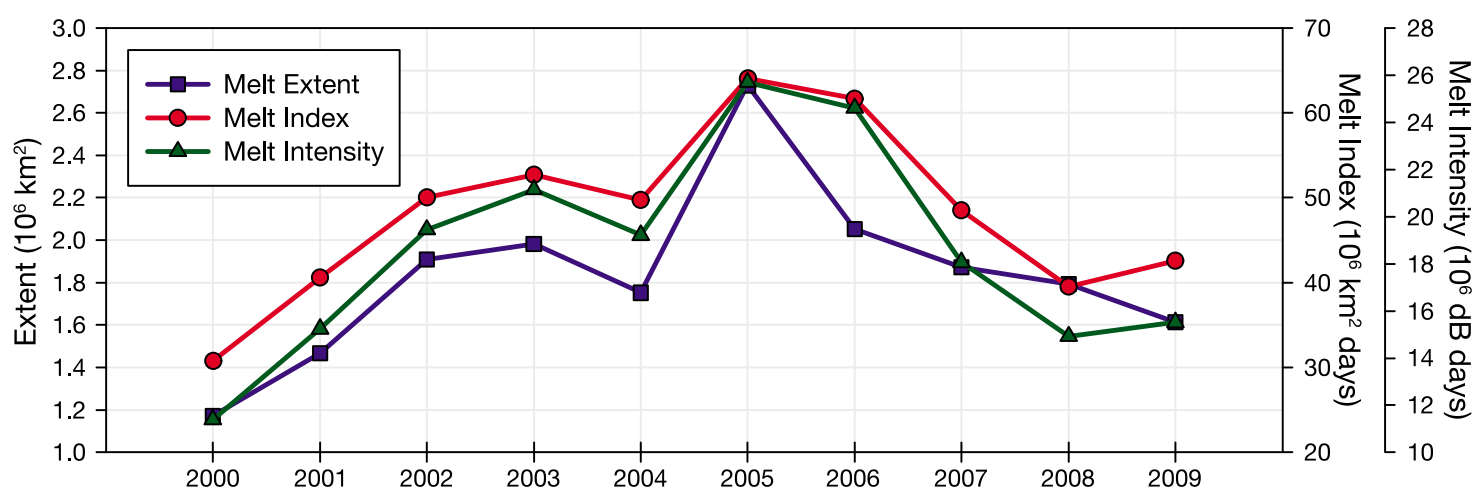

Figure 5. Variations in total annual melt extent (blue), melt index (red), and melt intensity (green) observed over the entire Antarctic continent.

along the continental margins and that nearly all ice shelves experience some melting each year. In the weak melting year of 2000 as defined by our melt metrics (Figure 5), the annual anomaly map reveals below average melting across nearly all of coastal Antarctica with the exception of Wilkins and George VI ice shelves on the Antarctic Peninsula (Figure 6). Causes of the 2005 peaks in all melt metrics (Figure 5) are also apparent in the melt duration anomaly maps. Nearly all ice shelves experience above average melting in 2005 with the exception of Larsen $\mathrm{C}$ on the Peninsula (Figure 6). Also noteworthy is extensive melting across much of the Ross Ice Shelf and extending over the Siple Coast into West Antarctica to elevations as high as $1700 \mathrm{~m}$. This finding is generally consistent with other studies [Nghiem et al., 2007;

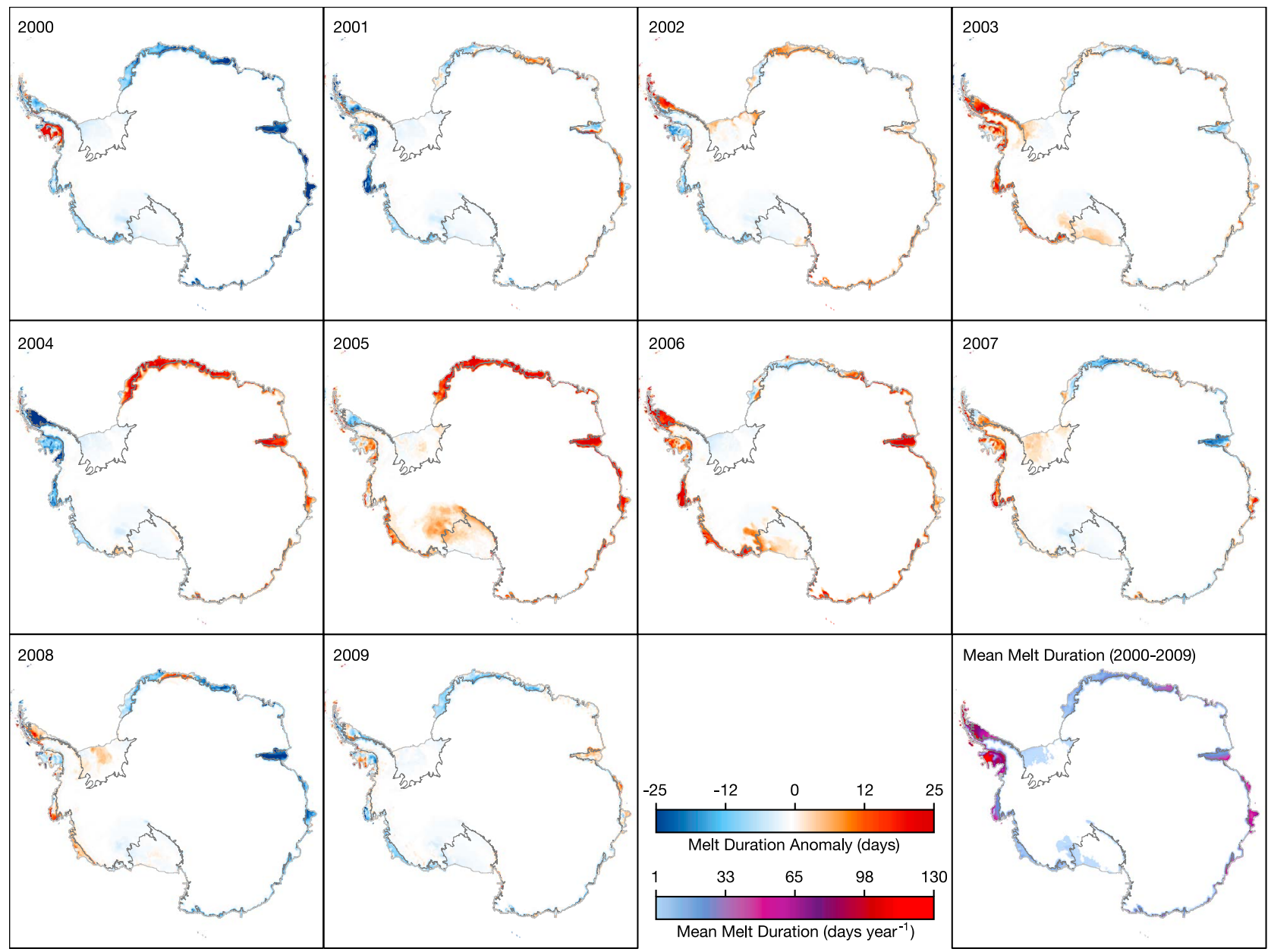

Figure 6. Annual maps of melt duration anomalies and the mean melt duration over the 2000-2009 period (lower right). Mean melt duration is shown only for pixels that melted at least one day on average over the time series. 


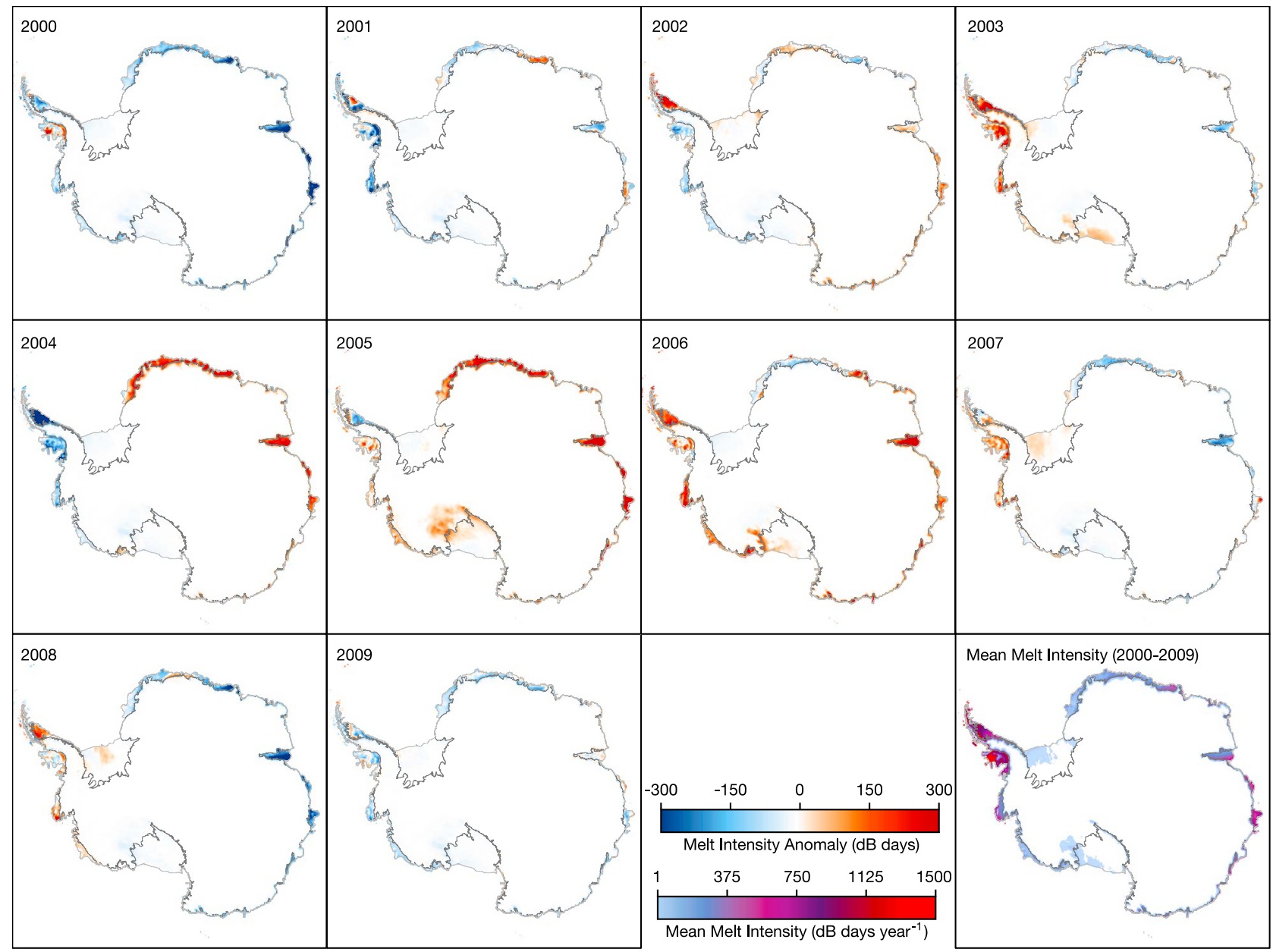

Figure 7. Annual maps of melt intensity anomalies and the mean melt intensity over the 2000-2009 period (lower right). Mean melt intensity is shown only for pixels that melted at least one day on average over the time series.

Tedesco et al., 2007], although we detect durations that are locally in excess of 2 weeks, about 1 week longer than those reported by Tedesco et al. [2007].

[23] The Antarctic Peninsula experiences the longest melt seasons, with portions of Wilkins, Larsen C, and George IV ice shelves as well as western Antarctic Peninsula outlet glaciers all melting $>100$ days $\mathrm{a}^{-1}$, on average (Figure 6). Beyond the Peninsula, the Shackleton and Amery ice shelves in East Antarctica experience upwards of 60 days $\mathrm{a}^{-1}$ of melting near their marine margins. A possible orographic influence on melting is also apparent along the Transantarctic Mountains in interior Ross Ice Shelf, with a small belt of melting occurring at least several days per year in most years (Figure 6).

[24] Figure 7 shows annual MDD-derived melt intensity anomaly maps and the mean melt intensity over the 10 years. Spatial patterns of melt duration anomalies (Figure 6) and melt intensity anomalies (Figure 7) are very similar both annually and when averaged over the decade. Underlying this similarity is the fact that the melt intensity metric incorporates both the duration of the melt season and the overall reduction in backscatter during melting. Thus, areas with long annual melt duration tend to have inherently greater melt intensity, resulting in a general proportionality between the two metrics particularly at the continental scale. Like melt duration, mean melt intensity is amplified regionally on the Antarctic Peninsula relative to the remainder of the continent. Divergences between duration and intensity are more apparent at regional and local scales, and are further explored in section 3.4.3.

\subsubsection{Melt Index Comparisons}

[25] Antarctic melt indices reported by several studies show wide ranging variability, with our values exceeding those previously reported by a factor of 1.3 to 2.6 (Figure 8), depending on the study and years compared. Although all other studies are based on SMMR and SSM/I PMW data, our radar scatterometer-based melt index is highly correlated with the published time series. A very strong relationship exists between our results and those reported by Tedesco [2009] $(\mathrm{r}=0.932, \mathrm{n}=9)$, although this correlation is slightly reduced if we augment their time series one year by Tedesco and Monaghan [2009] $(\mathrm{r}=0.876, \mathrm{n}=10)$ (assuming a consistent MEMLS2-based methodology in both PMW studies). Underlying this weakened correlation is that Tedesco and Monaghan [2009] report that the 2009 melt index was the lowest ever recorded, although our data indicate 2000 was lower than 2009 by about $12 \times 10^{6} \mathrm{~km}^{2}$ days. In fact, our results show that although the total melt extent 


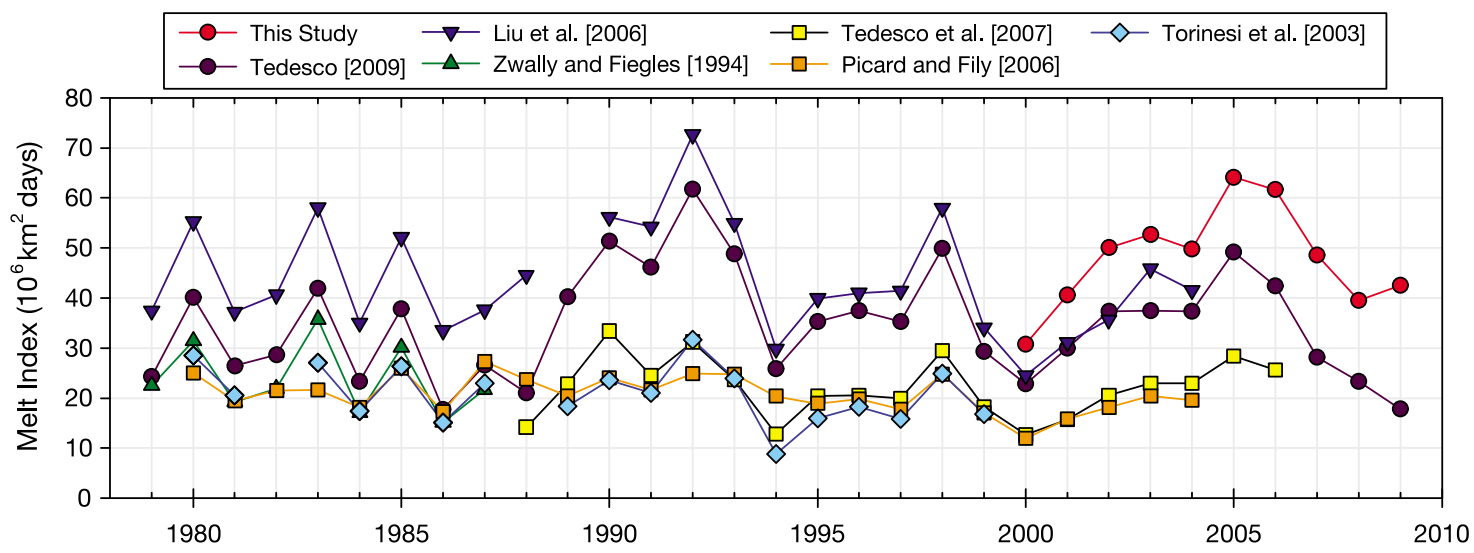

Figure 8. Comparison of continent-wide melt indices from this study (red line) and several other studies. Whereas this study employs radar scatterometer data, other studies determined melt index from passive microwave data. The 2009 melt index reported by Tedesco and Monaghan [2009] is plotted as a continuation of MEMLS2 results from Tedesco [2009].

decreased in 2009, the continent-wide melt index increased in this summer (Figure 5), primarily driven by enhanced melting across East Antarctica (see section 3.4).

[26] Inherent to our higher melt index values is greater melt detection over both space and time. Map-based comparisons between our results (see annual duration maps in the OAM) and those of Tedesco [2009, Figure 10] reveal that in 2008 we detect $10+$ greater melting days over Wilkins Ice Shelf, in addition to melting over much of the Amery Ice Shelf that is mostly undetected in the other study. Further comparison of our 2009 melt duration map to the same map by Tedesco and Monaghan [2009, Figure 2], reveals that our methodology detects melt over much wider areas across all of coastal Antarctica, particularly over ice shelves in East Antarctica. In addition, we record much longer durations in places such as Wilkins Ice Shelf on the Antarctic Peninsula ( $\sim 120$ days versus $\sim 90$ days of Tedesco and Monaghan [2009]).

\subsection{Regional Scale Melt Metrics}

\subsubsection{Melt Extent, Index, and Intensity}

[27] We calculate the three melt metrics (extent, index, and intensity) for seven specific regions of Antarctica: (1) Antarctic Peninsula, (2) Marie Byrd Land, (3) Ross Ice Shelf, (4) Wilkes Land, (5) Amery Ice Shelf, (6) Dronning Maud Land, and (7) Ronne-Filchner Ice Shelf (Figure 9). These regions are delineated based on our melting maps to be physically meaningful and process-oriented and are therefore similar but not identical to those by Torinesi et al. [2003] and Tedesco et al. [2007]. No melting is detected in interior areas not included in a defined region. Similar to continent-wide indices, no trends are apparent over the regional time series and all metrics show a high degree of interannual variability. In general, slight increases from the beginning of the time series lead to mid-decade peaks, followed by a variety of decreases and increases across the regions. Some coherence exists between regions, particularly that of Wilkes Land, Amery Ice Shelf, and Dronning Maud Land (East Antarctica) where signs and relative magnitude of change are similar. Marie Byrd Land and the Ross Ice Shelf regions (West Antarctica) also show similar patterns with mid-decade maxima in all metrics. The Antarctic Peninsula and Ronne-Filchner regions appear the most distinct, responding nearly inversely relative to the interannual variations recorded in other regions. This behavior is also observed in our anomaly maps (e.g., 2000 and 2004 in Figures 6 and 7).

[28] Similarities exist among the melt metrics within any given region (Figure 9), although distinctions are generally more apparent regionally than at the continental scale (Figure 5). The melt index and melt intensity metrics are strongly correlated in all regions. It is also apparent that these metrics are both dissimilar to melt extent, and therefore provide additional important information on melting dynamics. Melt metrics for the Antarctic Peninsula are least intercorrelated: In 4 of the 10 years, the melt index and intensity vary inversely to melt extent (e.g., 2000 to 2001 in Figure 9). Part of this can be attributed to the low melt extent variability (maximum $15 \%$ interannual change) relative to higher variability in the melt index (up to $32 \%$ interannual change) and the melt intensity (up to $45 \%$ interannual change). Differences in the amplitudes of interannual variability also enable further insight into melting processes. For example, the 2003 melt index and melt intensity increased by $9 \%$ and $18 \%$, respectively, suggesting meltwater production outpaced increases in melt duration and extent.

[29] Table 1 documents the considerably higher prevalence of melting on the Antarctic Peninsula relative to the rest of the continent. The average melt index for the Peninsula is nearly equal to that of the remaining continent combined, although its average melt extent only accounts for one-fifth of the total continental melt extent. This results from a smaller area that melts for much greater durations than the remaining continent. Furthermore, even with a much reduced melt area, the total average melt intensity of the Antarctic Peninsula exceeds that of the entire rest of the continent. For most years, the melt intensity on the Peninsula is 2.5 to 10 times that of the other regions (Figure 9). Rarely does melt intensity in any other region reach closely comparable values to that occurring on the Peninsula, and excluding the major ice shelves (Ross and Ronne-Filchner), these other regions have overall comparable melt intensities. 

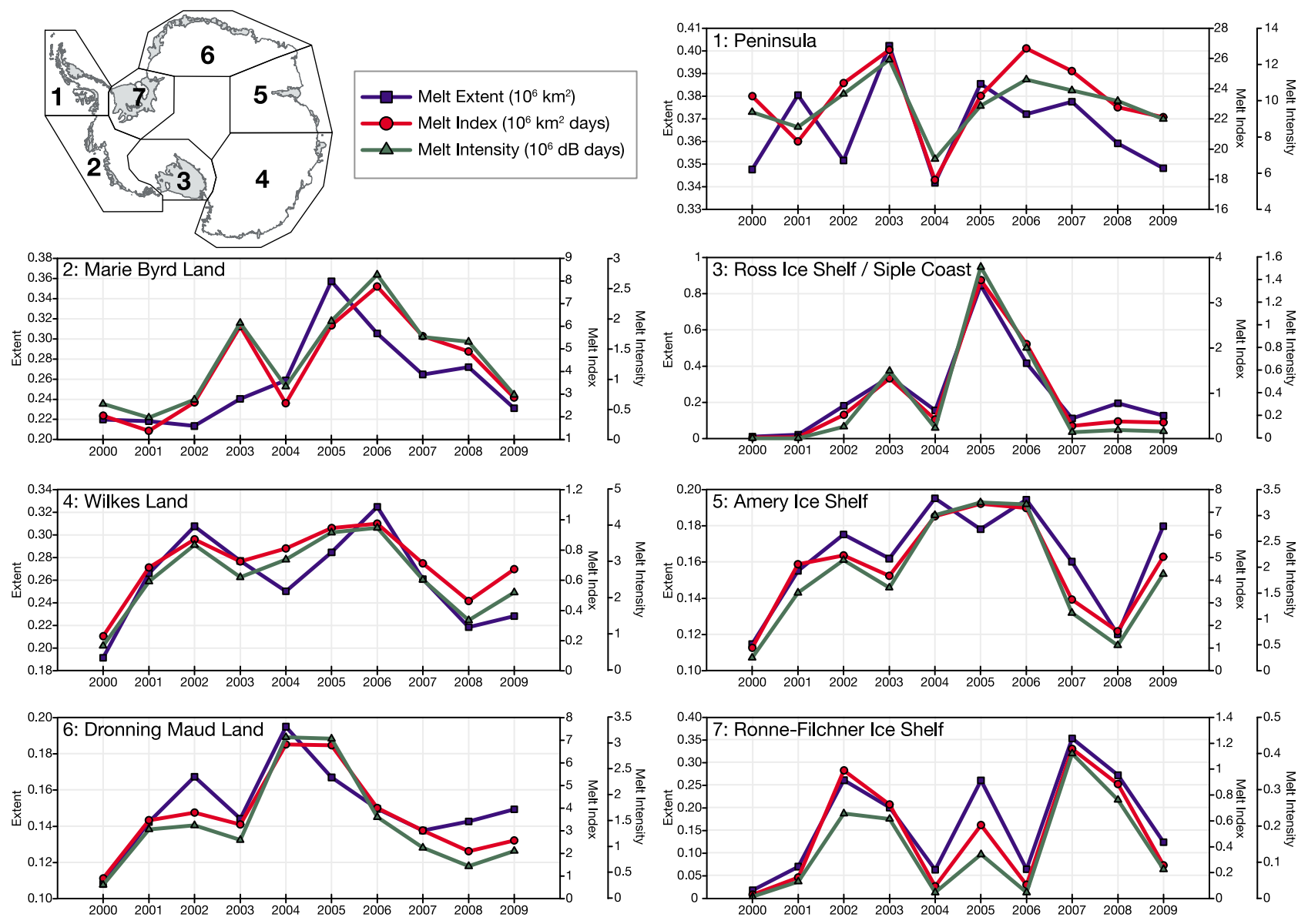

Figure 9. Regional variations in the melt extent (blue), index (red), and intensity (green) defined by the boundaries in the map. Note that the scales for each region are unique.

\subsubsection{Localized Comparisons in Melt Duration and Intensity}

[30] Because melt season duration is inherent in calculations of melt intensity, the two metrics often co-vary over space (e.g., Figures 6 and 7) and time (e.g., Figures 5 and 9). However, subtle yet important differences exist between duration and intensity at certain locations, with these divergences providing critical insight into melt processes. To facilitate the distinction between these two parameters, we show regional maps of duration and intensity that include regionally specific color scales and spatial profiles to highlight similarities and differences (Figure 10).

[31] From these maps, it is apparent that areas of peak melt duration do not always coincide with peak intensity (Figure 10). Maximum Antarctic Peninsula melt duration occurs on the ice fields and outlet glaciers of the western coast, whereas maximum melt intensity occurs over Wilkins Ice Shelf and is similarly strong over northern Larsen C Ice Shelf. On Amery Ice Shelf, both duration and intensity are spatially concentrated along the eastern and northern margins of the ice shelf, however intensity declines more rapidly away from the marine terminus. An interior peak in mean melt duration $\left(\sim 40\right.$ days $\left.\mathrm{a}^{-1}\right)$ coincides with a greatly

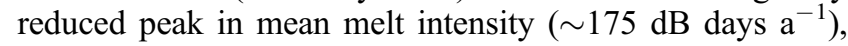
approximately half the intensity associated with similar durations in the center of the ice shelf (Figure 10, profile C). Surface melting occurs over much of the lower elevation ice shelves (generally $<30 \mathrm{~m}$ ) in the Amundsen Sea Embayment. A profile transecting the Abbot, Cosgrove, and Pine Island Glacier ice shelves shows a strong elevational control with pronounced melting occurring on the ice shelves and far reduced melting over the higher elevation $(\geq 200 \mathrm{~m})$ peninsulas (Figure 10, profile D). In this region, peak melt duration occurs over the glaciers draining northern Thurston Island, yet peak melt intensity occurs on the westernmost Abbot Ice Shelf.

[32] Figure 11 shows the interannual variability of melt duration and melt intensity at the points referenced in Figure 10. In general and as seen across larger spatial scales, interannual variations in melt duration and intensity are strongly correlated. This fact is increasingly apparent at

Table 1. Mean Melt Metrics (Melt Extent, Index, and Intensity) Over the 10 Years for the Antarctic Peninsula (Region 1 in Figure 9) Compared to the Sum of the Mean Annual Metrics From the Remaining Continent (Regions 2-7 in Figure 9)

\begin{tabular}{lccc}
\hline \multicolumn{1}{c}{ Metric } & $\begin{array}{c}\text { Antarctic } \\
\text { Peninsula } \\
\text { Average }\end{array}$ & $\begin{array}{c}\text { Remaining } \\
\text { Continent }\end{array}$ & $\begin{array}{c}\text { AP Percentage } \\
\text { of Total }\end{array}$ \\
\hline Extent $\left(10^{6} \mathrm{~km}^{2}\right)$ & 0.367 & 1.47 & $20 \%$ \\
Index $\left(10^{6} \mathrm{~km}^{2}\right.$ days $)$ & 23.3 & 24.6 & $49 \%$ \\
Intensity $\left(10^{6} \mathrm{~dB}\right.$ days $)$ & 9.78 & 8.72 & $53 \%$ \\
\hline
\end{tabular}



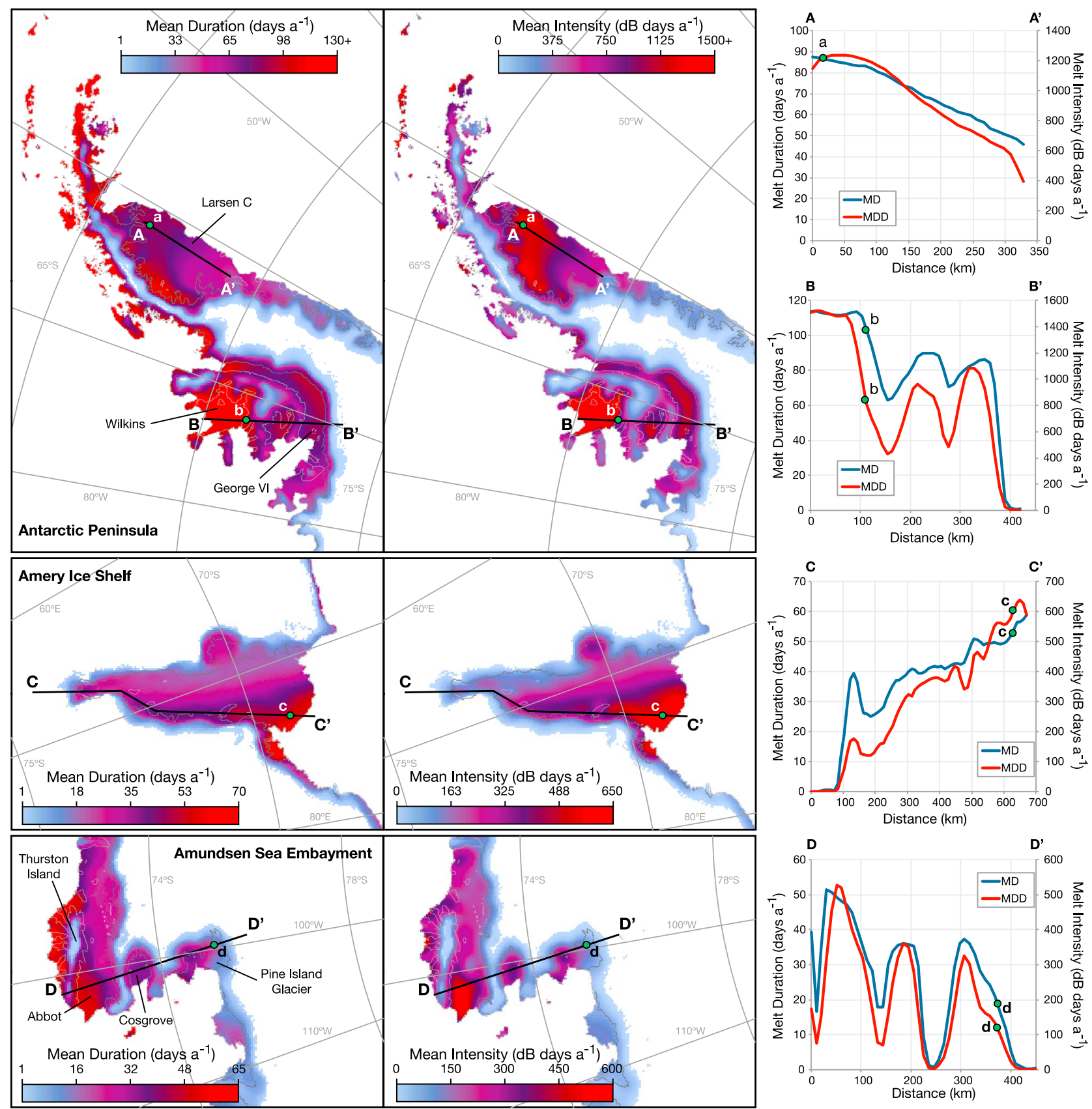

Figure 10. Regional perspectives of the spatial variations in (left maps) mean melt duration and (right maps) mean melt intensity. Maps are limited to areas with a minimum of one melting day on average as in Figures 6 and 7. Color scales are unique for each region to highlight spatial differences. Spatial profiles of melt duration (MD, blue lines) and melt intensity (MDD, red lines) indicated by black transect lines on maps are plotted on the right. Temporal profiles of MD and MDD at locations of green points are shown in Figure 11.

locations of low melt duration (e.g., Pine Island Glacier in Figure 11), where much of the MDD variability is controlled by melt duration. However, areas of heightened melt duration tend to display increased divergence between melt intensity and duration simultaneous with decreased correlation between these parameters (Figure 11). Examples of the latter are apparent in the form of disproportional magnitudes of interannual change and particularly as anticorrelations between duration and intensity over Larsen $\mathrm{C}$ and Wilkins ice shelves (e.g., 2008 to 2009 in Figure 11a; 2007 to 2008 in Figure 11b). These observations therefore illustrate the enhanced information provided by the MDD melt intensity metric, particularly in areas of long melt duration.

\section{Discussion}

[33] Melt index values from QuikSCAT follow interannual variations that are similar to those previously published 


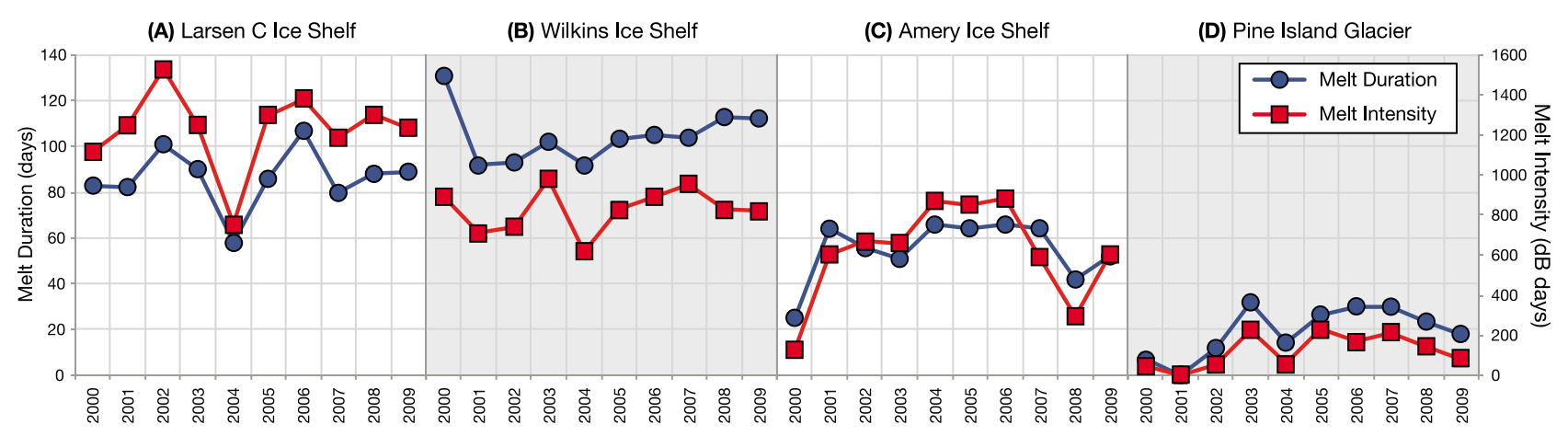

Figure 11. Temporal variations in melt duration and melt intensity at the point locations (lettered green dots) shown in Figure 10.

using PMW instruments, but are larger owing to both greater spatial and temporal melt detection. We also note the large divergences among the melt indices of PMW studies alone (Figure 8), which have been attributed to varying detection methodologies and LWC sensitivities [Tedesco, 2009]. Although in theory the detection approach of our study and the MEMLS2 approach of Tedesco [2009] are optimally sensitive to brief melting and similarly low LWC thresholds $(<1 \%)$, our mean melt index over $2000-2009$ is still $\sim 19 \%$ larger than that derived from SSM/I data in the other study. Without direct comparison among QuikSCAT, PMW, and in situ melt observations, specific attribution of our larger values remains difficult. However, we believe our heightened melt index reflects a contribution of at least three factors. First, we use afternoon local time-of-day data for maximum temporal correspondence between QuikSCAT overpass and melting. As such, our results are not affected by the increasingly unfavorable Antarctic observation hours of SMMR and SSM/I reported by Picard and Fily [2006] to introduce negative melting biases in these data sets. Second, QuikSCAT data have a much finer spatial resolution (4.45 km versus $25 \mathrm{~km}$ of SSM/I), and may therefore enable melt detection in high relief areas represented by much coarser PMW pixels (i.e., higher average elevation). Finally, comparative studies over Greenland find QuikSCAT more sensitive to melting than PMW instruments [Steffen et al., 2004; Ashcraft and Long, 2006; Tedesco, 2007] and Moderate Resolution Imaging Spectroradiometer (MODIS) albedo and land surface temperature measurements [Hall et al., 2009]. Detection of subsurface LWC below frozen surfaces is reported to be a contributing factor for this higher sensitivity [Ashcraft and Long, 2006; Hall et al., 2009]. Importantly, energy balance modeling suggests the prevalence of subsurface melting across costal Antarctica $(>0 \%$ LWC several $\mathrm{cm}$ to $1+\mathrm{m}$ depth) owing to shortwave radiation penetration and a lack of subsurface longwave cooling [Liston and Winther, 2005], processes that may also result in underestimation of total melt from temperature-index models [Sergienko and Macayeal, 2005]. Although scattering from near-surface ice lenses may be significant enough to obscure percolated LWC in the subsurface [Matzler et al., 1997; Nghiem et al., 2001], this scattering effect may not play as large of a role if subsurface melt exists owing to positive subsurface energy balances. Thus, it is probable that detection of at least some subsurface melt contributes to our melt indices. Critical insight into the relative importance of these factors can be achieved through comparison of melt records from satellites, modeling, and in situ observations.

[34] The consistently higher melt indices of this study suggest that past studies of Antarctic surface melting may underestimate the process. Strong correlations between our melt index time series and those of previous studies suggest the repercussions of our increased sensitivity do not negate previous findings (e.g., high interannual variability). However, increased melt detection can result in changes to the relative ranking of melting years (e.g., our results show the 2000 melt index was lower than the 2009 melt index reported to be the lowest by Tedesco and Monaghan [2009]), and thus inferences based on such rankings may require reevaluation. Although it remains difficult to assess the physical implications of our enhanced melt detection, we believe our QuikSCAT-derived results to be a more accurate and comprehensive depiction of surface melting across the continent than provided by earlier studies. These results can therefore be used to more fully assess and contextualize the results from both modeled and empirical melt studies.

[35] Strong correlations between the melt index and melt intensity metrics are attributable to their likewise inclusion of seasonal melt duration. Importantly, this relationship allows the interpretation of longer-term, continental-scale melt index calculations derived from PMW instruments (e.g., Figure 8) as representing the relative melt intensity. However, we find important distinctions between the index and intensity, which are increasingly apparent at regional and sub-regional scales. Our results illustrate that areas of peak melt duration do not necessarily coincide with that of peak melt intensity, and in some instances, the two vary nonlinearly over space and time. These discrepancies appear to be most prevalent in areas of high melt duration such as the Antarctic Peninsula. This suggests some caution must be exercised when interpreting spatiotemporal melt metrics alone (index and duration) as a proxy for melt intensity at sub-continental scales. In these instances, scatterometerbased melt intensity offers a previously unobtainable and more encompassing assessment of melt variability.

[36] One clear advantage of the increased melt sensitivity of QuikSCAT is that we are able to detect melt over areas previously thought to rarely melt. For instance, we detect locally extensive melt on leeward side of the Transantarctic Mountains as early as 2002 and occurring in 7 of 10 years studied (Figure 6; OAM). Previous researchers using PMW radiometers detected melt across this area for the first time in 
2005 [Tedesco et al., 2007], which Liu et al. [2006] attributed to adiabatic warming of descending katabatic air masses. The fine spatial resolution afforded by QuikSCAT also allows insight into more localized areas likely affected by similar processes. We speculate that two areas of locally heightened melting on the Amery Ice Shelf (Figure 10) may be similarly linked to adiabatic compression and warming of descending air masses coupled with the lower albedo of this blue-ice region. Perhaps more importantly, we capture locally heightened melt duration and intensity on the westernmost (interior) Larsen C Ice Shelf (Figure 10). This is an area that Marshall et al. [2006] reported increased air temperatures owing to downslope movement of air masses after passage over the orographic barrier of the Antarctic Peninsula, a finding they linked to strong zonal winds during positive phases of the Southern Annular Mode (SAM). As the northeastern Antarctic Peninsula is subject to surface ponding linked to ice shelf destabilization [e.g., van den Broeke, 2005], more thorough inspection of scatterometerbased melt intensity and its linkages to SAM could be particularly revealing.

[37] In attempting to understand the diverse drivers of Antarctic surface melting, recent research highlights the importance of SAM and the Southern Oscillation Index (SOI), which describes the atmospheric component of the El-Niño Southern Oscillation (ENSO). These studies find strong SAM and SOI influences on high southern latitude atmospheric circulation patterns and poleward propagation of heat conducive to surface melting [Torinesi et al., 2003; Tedesco and Monaghan, 2009]. Specifically, negative melting (index and extent) anomalies are significantly correlated with the combined positive phase anomalies of SAM and SOI over the 1979-2009 period [Tedesco and Monaghan, 2009]. We similarly find continental-scale melt intensity to be significantly anticorrelated to SAM $(\mathrm{r}=$ $-0.717, \mathrm{p}<0.05$ ), and to SAM and SOI combined (multiple $\mathrm{r}=-0.789, \mathrm{p}<0.05$ ) when using ONDJ (October, November, December, January) SAM/SOI averages, as in previous studies. No significant relationships are found between continental-scale melt intensity and SOI alone, perhaps because intensity is largely dominated by variability on the Antarctic Peninsula (e.g., Table 1) and SOI is known to have varying and sometimes conflicting impacts on this region [Turner, 2004]. Likewise, at regional scales, we find no significant teleconnections between SAM/SOI and melt intensity at the $95 \%$ confidence interval; however, lack of significant correlations is also potentially attributable to our short time series.

[38] Of the 10 years documented in this study, 2005 stands out as having the greatest melt as measured in all metrics, particularly across the Ross Ice Shelf region that contributes $30 \%$ of the total Antarctic melt extent in this year. Observation of daily maps reveals that melting appears first over the upper MacAyeal ice stream of the Siple Coast on 2 January 2005, spreads westward onto the Ross Ice Shelf the following day, and remains relatively confined in these areas before encompassing the entire region on 6 January 2005, coinciding with melt detection in PMW data [Tedesco et al., 2007]. Coincident with these events is cyclonic (low pressure) atmospheric circulation suggested by strong clockwise circulation of sea ice in the entire Ross and western Amundsen seas clearly discernible in our raw QuikSCAT data and confirmed in daily NCEP/NCAR reanalysis mean sea level pressure (MSLP) data [Kalnay et al., 1996]. Sea ice in this region (particularly in the eastern Ross Sea) had nearly disappeared by January 2005 leading to one of the lowest recorded minimum sea ice extents in the Ross Sea region [Cavalieri and Parkinson, 2008]. Both cyclonic circulation and reduced sea ice cover favor advection of oceanic heat and moisture into the region, potentially contributing to the large scale melting. Contextualizing these observations, events of similar scale across the region $\left(>5.0 \times 10^{6} \mathrm{~km}^{2}\right)$ occur only about once per decade (1983 and 1992 of Liu et al. [2006], 2005 in this study). In all of these years SOI is in negative phases, with strong El Niño conditions in 1983 and 1992 and a weak-moderate El Niño in 2005. SAM was near its mean during the latter two years, but strongly negative in 1983, suggesting lack of a strong influence. Warmer air temperatures and reduced sea ice in the Ross-Amundsen Sea sector are consistent with negative SOI forcing [e.g., Yuan, 2004; Turner, 2004; Bertler et al., 2006]. A dominant positive MSLP anomaly in the Bellingshausen Sea typical of El Niño [e.g., Turner, 2004] combined with cyclonic circulation over the Ross Sea can act to increase fluxes of marineadvected heat, moisture, and clouds to this region and West Antarctica overall [e.g., Nicolas and Bromwich, 2011]. Heat advection and inland propagation is further enhanced by reduced sea ice cover and the low relief of the Ross Ice Shelf and Siple Coast [e.g., Das and Alley, 2008]. Thus, although conditions in West Antarctic are highly variable owing to the combined influence of multiple climate modes [Yuan and $\mathrm{Li}$, 2008], conditions appear favorable for large scale melting across the Ross Ice Shelf region and particularly during negative phases of SOI.

[39] Quantitative, satellite-based melt intensity retrieval is clearly desirable. The strong MDD-PDD correlation (Figure 3b) suggests MDD variability is statistically attributable to spatial and temporal variability in PDD. As such, it is tempting to invert this relationship to map PDD for application in temperature-index melt modeling. In this approach, meltwater production ( $M$ in $\mathrm{mm})$ is calculated as the product of PDD $\left({ }^{\circ} \mathrm{C}\right.$ days) and degree-day factors (DDF in $\mathrm{mm}^{\circ} \mathrm{C}^{-1}$ day $^{-1}$ ) $[$ Hock, 2005]. These spatially heterogeneous DDF encompass physical snowpack properties and associated differences in the relative importance of energy balance components [Hock, 2003]. However, since MDD reflect variations in snowpack LWC, they are more analogous to $M$ than PDD, confounding simple inversion of MDD to derive PDD. The most ideal calibration of QuikSCATbased melt intensity would therefore involve independent comparison of MDD to in situ meltwater production $(M)$, as we did for Neumayer Station (Figure 4). Here, the strong MDD- $M$ linear regressions indicate QuikSCAT MDD can be inverted to map meltwater production. Nevertheless, it is important to recognize that the backscatter reductions inherent to MDD are also sensitive to variable snowpack and wet snow layer properties. If these near-surface snow and firn properties remain consistent, as might be reasonably assumed over flat and low-elevation ice shelves, regionally or locally specific quantitative melt intensity retrieval may be possible within acceptable error limits given sufficient ground truthing. Further comparison of in situ meltwater production to scatterometer-based melt intensity is clearly 
warranted and can provide critical insight into understanding how satellite radar directly relate to meltwater production.

\section{Conclusions}

[40] In this study we document surface melting dynamics across Antarctica using radar backscatter data from QuikSCAT. Observations of melt duration, melt extent, and the melt index produced in this study are larger than those found in other studies. We attribute this to the increased sensitivity of QuikSCAT owing to observations during afternoon local time, its increased spatial resolution, and its reported higher sensitivity to liquid water. Divergences among melt metrics produced using different methods suggest further research is warranted to more fully assess the relative capabilities and limitations of these approaches. Temporally integrated backscatter reductions during melting are significantly correlated to PDD and modeled meltwater production. These findings support the use of QuikSCAT for retrieval of at minimum relative melt intensity. Melt duration and melt intensity are broadly correlated at large spatial scales, suggesting the melt index (including those derived from PMW satellites) can be interpreted as representing relative melt intensity. However, melt duration, index, and intensity do not always vary linearly over space and time, particularly in regions of heightened melting like the Antarctic Peninsula. In these instances, melt intensity derived from QuikSCAT is a more revealing metric for documenting the variability in liquid water produced during melting. Abrupt failure of the QuikSCAT antenna in late 2009 prevents ongoing measurements, but findings here are likely applicable to the similarly designed and currently operating Ku-band Oceansat-2 scatterometer. Teleconnections found between melt intensity and the SAM and SOI further suggest the coupling of the high southern latitudes to the global climate system. Likewise, extreme melting events across the Ross Ice Shelf and West Antarctica appear to be enhanced during El Niño conditions. Applications of scatterometerbased melt intensity for determining liquid water production are promising and can offer previously unobtainable insight into the total impacts of melting. These measurements therefore offer new perspectives on the spatiotemporal characteristics of surface melting across the Antarctic, a particularly critical process to monitor when considering the stability of Antarctic ice shelves under sustained atmospheric warming.

[41] Acknowledgments. Support for this research was provided by NASA grant NNX10AP09G and NSF grant ANT-063203. We would like to thank the BYU Scatterometer Climate Pathfinder project and David Long for providing the QuikSCAT data used in this study. We are thankful for the careful comments of three anonymous reviewers and the associate editor who greatly improved earlier versions of this manuscript

\section{References}

Ashcraft, I. S., and D. G. Long (2006), Comparison of methods for melt detection over Greenland using active and passive microwave measurements, Int. J. Remote Sens., 27(12), 2469-2488, doi:10.1080/ 01431160500534465.

Bertler, N. A. N., T. R. Naish, P. A. Mayewski, and P. J. Barrett (2006), Opposing oceanic and atmospheric ENSO influences on the Ross Sea Region, Antarctica, Adv. Geosci., 6, 83-86, doi:10.5194/adgeo-6-832006.
Cavalieri, D. J., and C. L. Parkinson (2008), Antarctic sea ice variability and trends, 1979-2006, J. Geophys. Res., 113, C07004, doi:10.1029/ 2007JC004564.

Cook, A. J., and D. G. Vaughan (2010), Overview of areal changes of the ice shelves on the Antarctic Peninsula over the past 50 years, Cryosphere, 4(1), 77-98, doi:10.5194/tc-4-77-2010.

Cuffey, K. M., and W. S. B. Paterson (2010), The Physics of Glaciers, 4th ed., Elsevier, Burllington, Mass.

Das, S. B., and R. B. Alley (2005), Characterization and formation of melt layers in polar snow: Observations and experiments from West Antarctica, J. Glaciol., 51, 307-312, doi:10.3189/172756505781829395.

Das, S. B., and R. B. Alley (2008), Rise in frequency of surface melting at Siple Dome through the Holocene: Evidence for increasing marine influence on the climate of West Antarctica, J. Geophys. Res., 113, D02112, doi:10.1029/2007JD008790.

Frey, K. E., L. C. Smith, and D. E. Alsdorf (2003), Controls on Eurasian coastal sea ice formation, melt onset and decay from ERS scatterometry: Regional contrasts and effects of river influx, Int. J. Remote Sens., 24(24), 5283-5315, doi:10.1080/0143116031000101684

Hall, D. K., S. V. Nghiem, C. B. Schaaf, N. E. DiGirolamo, and G. Neumann (2009), Evaluation of surface and near-surface melt characteristics on the Greenland ice sheet using MODIS and QuikSCAT data, J. Geophys. Res., 114, F04006, doi:10.1029/2009JF001287.

Haran, T., J. Bohlander, T. Scambos, T. Painter, and M. Fahnestock (2005), MODIS Mosaic of Antarctica (MOA) Image Map, http://nsidc.org/data/ nsidc-0280.html, Natl. Snow and Ice Data Cent., Boulder, Colo. [Updated in 2006.]

Hicks, B. R., and D. G. Long (2005), Improving temporal resolution of SIR images for QuikSCAT in the polar regions, Tech. Rep. MERS 05-02, Brigham Young Univ., Provo, Utah.

Hock, R. (2003), Temperature index melt modelling in mountain areas, J. Hydrol., 282(1-4), 104-115, doi:10.1016/S0022-1694(03)00257-9.

Hock, R. (2005), Glacier melt: A review of processes and their modelling, Prog. Phys. Geogr., 29(3), 362-391, doi:10.1191/0309133305pp453ra.

Hock, R., M. de Woul, V. Radić, and M. Dyurgerov (2009), Mountain glaciers and ice caps around Antarctica make a large sea-level rise contribution, Geophys. Res. Lett., 36, L07501, doi:10.1029/2008GL037020.

Kalnay, E., et al. (1996), The NCEP/NCAR 40-year reanalysis project, Bull. Am. Meteorol. Soc., 77(3), 437-471, doi:10.1175/1520-0477(1996) 077<0437:TNYRP $>2.0$. CO;2

Kendra, J. R., K. Sarabandi, and F. T. Ulaby (1998), Radar measurements of snow: Experiment and analysis, IEEE Trans. Geosci. Remote Sens., 36(3), 864-879, doi:10.1109/36.673679.

King, J. C., and J. Turner (1997), Antarctic Meteorology and Climatology, Cambridge Univ. Press, New York, doi:10.1017/CBO9780511524967.

Kuipers Munneke, P., M. R. van den Broeke, J. T. M. Lenaerts, M. G. Flanner, A. S. Gardner, and W. J. van de Berg (2011), A new albedo parameterization for use in climate models over the Antarctic ice sheet, J. Geophys. Res., 116, D05114, doi:10.1029/2010JD015113.

Kunz, L., and D. Long (2006), Melt detection in Antarctic ice shelves using scatterometers and microwave radiometers, IEEE Trans. Geosci. Remote Sens., 44(9), 2461-2469.

Liston, G. E., and J.-G. Winther (2005), Antarctic surface and subsurface snow and ice Melt Fluxes, J. Clim., 18(10), 1469-1481, doi:10.1175/ JCLI3344.1

Liu, H., L. Wang, and K. C. Jezek (2006), Spatiotemporal variations of snowmelt in Antarctica derived from satellite scanning multichannel microwave radiometer and Special Sensor Microwave Imager data (1978-2004), J. Geophys. Res., 111, F01003, doi:10.1029/ 2005JF000318.

Long, D. G. (2010), Standard BYU QuikSCAT and Seawinds land/ice image products, report, BYU Cent. for Remote Sens., Microwave Earth Remote Sens. Lab, Provo, Utah. [Available from http://www.scp.byu. edu/docs/pdf/QscatReport6.pdf]

Marshall, G. J., A. Orr, N. P. M. van Lipzig, and J. C. King (2006), The impact of a changing Southern Hemisphere Annular Mode on Antarctic Peninsula summer temperatures, J. Clim., 19(20), 5388-5404, doi:10.1175/JCLI3844.1.

Matzler, C., T. Strozzi, T. Weise, D.-M. Floricioiu, and H. Rott (1997), Microwave snowpack studies made in the Austrian Alps during the SIR-C/X-SAR experiment, Int. J. Remote Sens., 18(12), 2505-2530, doi:10.1080/014311697217440.

Morris, E. M., and D. G. Vaughan (2003), Spatial and temporal variation of surface temperature on the Antarctic Peninsula and the limit of viability of ice shelves, in Antarctic Peninsula Climate Variability: Historical and Paleoenvironmental Perspectives, edited by E. Domack et al., Antarct. Res. Ser., 79, pp. 61-68, AGU, Washington, D. C. 
Nagler, T., and H. Rott (2000), Retrieval of wet snow by means of multitemporal SAR data, IEEE Trans. Geosci. Remote Sens., 38(2), 754-765, doi:10.1109/36.842004.

Nghiem, S. V., and W. Y. Tsai (2001), Global snow cover monitoring with spaceborne Ku-band scatterometer, IEEE Trans. Geosci. Remote Sens., 39(10), 2118-2134, doi:10.1109/36.957275.

Nghiem, S. V., R. Kwok, S. H. Yueh, J. A. Kong, C. C. Hsu, M. A Tassoudji, and R. T. Shin (1995), Polarimetric scattering from layered media with multiple species of scatterers, Radio Sci., 30(4), 835-852, doi:10.1029/95RS01247.

Nghiem, S. V., K. Steffen, R. Kwok, and W. Y. Tsai (2001), Detection of snowmelt regions on the Greenland ice sheet using diurnal backscatter change, J. Glaciol., 47, 539-547, doi:10.3189/172756501781831738.

Nghiem, S. V., K. Steffen, G. Neumann, and R. Huff (2005), Mapping of ice layer extent and snow accumulation in the percolation zone of the Greenland ice sheet, J. Geophys. Res., 110, F02017, doi:10.1029/ 2004JF000234.

Nghiem, S. V., K. Steffen, G. Neumann, and R. Huff (2007), Snow accumulation and snowmelt monitoring in Greenland and Antarctica, Dyn. Planet, 130, 31-38.

Nicolas, J. P., and D. H. Bromwich (2011), Climate of West Antarctica and influence of marine air intrusions*, J. Clim., 24(1), 49-67, doi:10.1175/ 2010JCLI3522.1.

Ohmura, A. (2001), Physical basis for the temperature-based melt-index method, J. Appl. Meteorol., 40, 753-761, doi:10.1175/1520-0450(2001) 040<0753:PBFTTB $>2.0 . \mathrm{CO} ; 2$.

Panday, P. K., K. E. Frey, and B. Ghimire (2011), Detection of the timing and duration of snowmelt in the Hindu Kush-Himalaya using QuikSCAT, 2000-2008, Environ. Res. Lett., 6(2), 024007, doi:10.1088/1748-9326/6/ 2/024007.

Picard, G., and M. Fily (2006), Surface melting observations in Antarctica by microwave radiometers: Correcting 26-year time series from changes in acquisition hours, Remote Sens. Environ., 104(3), 325-336, doi:10.1016/j.rse.2006.05.010.

Picard, G., M. Fily, and H. Gallee (2007), Surface melting derived from microwave radiometers: A climatic indicator in Antarctica, Ann. Glaciol., 46, 29-34, doi:10.3189/172756407782871684.

Pritchard, H. D., and D. G. Vaughan (2007), Widespread acceleration of tidewater glaciers on the Antarctic Peninsula, J. Geophys. Res., 112, F03S29, doi:10.1029/2006JF000597.

Rignot, E., G. Casassa, P. Gogineni, W. Krabill, A. Rivera, and R. Thomas (2004), Accelerated ice discharge from the Antarctic Peninsula following the collapse of Larsen B ice shelf, Geophys. Res. Lett., 31, L18401, doi:10.1029/2004GL020697.

Rotschky, G., T. V. Schuler, J. Haarpainter, J. Kohler, and E. Isaksson (2011), Spatio-temporal variability of snowmelt across Svalbard during the period 2000-08 derived from QuikSCAT/SeaWinds Scatterometry, Polar Res., 30, 5963, doi:10.3402/polar.v30i0.5963.

Scambos, T. A., C. Hulbe, M. Fahnestock, and J. Bohlander (2000), The link between climate warming and break-up of ice shelves in the Antarctic Peninsula, J. Glaciol., 46, 516-530, doi:10.3189/172756500781833043.

Scambos, T. A., J. A. Bohlander, C. A. Shuman, and P. Skvarca (2004), Glacier acceleration and thinning after ice shelf collapse in the Larsen B embayment, Antarctica, Geophys. Res. Lett., 31, L18402, doi:10.1029/ 2004GL020670.

Sergienko, O., and D. R. Macayeal (2005), Surface melting on Larsen Ice Shelf, Antarctica, Ann. Glaciol., 40, 215-218, doi:10.3189/ 172756405781813474.

Shepherd, A., D. Wingham, D. Wallis, K. Giles, S. Laxon, and A. V. Sundal (2010), Recent loss of floating ice and the consequent sea level contribution, Geophys. Res. Lett., 37, L13503, doi:10.1029/2010GL042496.

Smith, L. C., Y. Sheng, R. R. Forster, K. Steffen, K. E. Frey, and D. E. Alsdorf (2003), Melting of small Arctic ice caps observed from ERS scatterometer time series, Geophys. Res. Lett., 30(20), 2034, doi:10.1029/ 2003GL017641.

Steffen, K., S. V. Nghiem, R. Huff, and G. Neumann (2004), The melt anomaly of 2002 on the Greenland Ice Sheet from active and passive microwave satellite observations, Geophys. Res. Lett., 31, L20402, doi:10.1029/2004GL020444.

Stiles, W. H., and F. T. Ulaby (1980), The active and passive microwave response to snow parameters: 1. Wetness, J. Geophys. Res., 85(C2), 1037-1044, doi:10.1029/JC085iC02p01037.

Tedesco, M. (2007), Snowmelt detection over the Greenland ice sheet from $\mathrm{SSM} / \mathrm{I}$ brightness temperature daily variations, Geophys. Res. Lett., 34 L02504, doi:10.1029/2006GL028466.

Tedesco, M. (2009), Assessment and development of snowmelt retrieval algorithms over Antarctica from K-band spaceborne brightness temperature (1979-2008), Remote Sens. Environ., 113(5), 979-997, doi:10.1016/j. rse.2009.01.009.

Tedesco, M., and A. J. Monaghan (2009), An updated Antarctic melt record through 2009 and its linkages to high-latitude and tropical climate variability, Geophys. Res. Lett., 36, L18502, doi:10.1029/2009GL039186.

Tedesco, M., W. Abdalati, and H. J. Zwally (2007), Persistent surface snowmelt over Antarctica (1987-2006) from 19.35 GHz brightness temperatures, Geophys. Res. Lett., 34, L18504, doi:10.1029/2007GL031199.

Torinesi, O., M. Fily, and C. Genthon (2003), Variability and trends of the summer melt period of Antarctic ice margins since 1980 from microwave sensors, J. Clim., 16(7), 1047-1060, doi:10.1175/1520-0442(2003) 016<1047:VATOTS $>2.0$.CO;2.

Turner, J. (2004), The El Niño-southern oscillation and Antarctica, Int. J. Climatol., 24(1), 1-31, doi:10.1002/joc.965.

Ulaby, F. T., and W. H. Stiles (1981), Microwave response of snow, $A d v$. Space Res., 1(10), 131-149, doi:10.1016/0273-1177(81)90389-6.

Ulaby, F. T., P. Siquera, A. Nashashibi, and K. Sarabandi (1996), Semiempirical model for radar backscatter from snow at 35 and $95 \mathrm{GHz}$, IEEE Trans. Geosci. Remote Sens., 34(5), 1059-1065, doi:10.1109/36.536521.

van den Broeke, M. (2005), Strong surface melting preceded collapse of Antarctic Peninsula ice shelf, Geophys. Res. Lett., 32, L12815, doi:10.1029/2005GL023247.

van den Broeke, M., G. König-Langlo, G. Picard, P. Kuipers Munneke, and J. Lenaerts (2010), Surface energy balance, melt and sublimation at Neumayer Station, East Antarctica, Antarct. Sci., 22(01), 87-96, doi:10.1017/ S0954102009990538.

Vaughan, D. G. (2006), Recent trends in melting conditions on the Antarctic Peninsula and their implications for ice-sheet mass balance and sea level, Arct. Antarct. Alp. Res., 38(1), 147-152, doi:10.1657/1523-0430 (2006)038[0147:RTIMCO]2.0.CO;2.

Wang, L., M. J. Sharp, B. Rivard, S. Marshall, and D. Burgess (2005), Melt season duration on Canadian Arctic ice caps, 2000-2004, Geophys. Res. Lett., 32, L19502, doi:10.1029/2005GL023962.

Wang, L., M. Sharp, B. Rivard, and K. Steffen (2007), Melt season duration and ice layer formation on the Greenland ice sheet, 2000-2004, J. Geophys. Res., 112, F04013, doi:10.1029/2007JF000760.

Wang, L., C. Derksen, and R. Brown (2008), Detection of pan-Arctic terrestrial snowmelt from QuikSCAT, 2000-2005, Remote Sens. Environ., 112(10), 3794-3805, doi:10.1016/j.rse.2008.05.017.

Winebrenner, D. P., E. D. Nelson, R. Colony, and R. D. West (1994), Observation of melt onset on multiyear Arctic sea ice using the ERS 1 synthetic aperture radar, J. Geophys. Res., 99(C11), 22,425-22,441, doi:10.1029/94JC01268.

Wismann, V. (2000), Monitoring of seasonal snowmelt on Greenland with ERS scatterometer data, IEEE Transactions Geosci. Remote Sens., 38(4), 1821-1826, doi:10.1109/36.851766.

Wolken, G. J., M. Sharp, and L. Wang (2009), Snow and ice facies variability and ice layer formation on Canadian Arctic ice caps, 1999-2005, J. Geophys. Res., 114, F03011, doi:10.1029/2008JF001173.

Yuan, X. (2004), ENSO-Related Impacts on Antarctic Sea Ice: A Synthesis of Phenomenon and Mechanisms, Antarct. Sci., 16(4), 415-425, doi:10.1017/S0954102004002238.

Yuan, X., and C. Li (2008), Climate modes in southern high latitudes and their impacts on Antarctic sea ice, J. Geophys. Res., 113, C06S91, doi:10.1029/2006JC004067.

Zwally, H. J., and S. Fiegles (1994), Extent and duration of Antarctic surface melt, J. Glaciol., 40, 463-476. 